\title{
A AGROECOLOGIA COMO MECANISMO DE EFETIVAÇÃO DOS OBJETIVOS DE DESENVOLVIMENTO SUSTENTÁVEL NO BRASIL
}

AGROECOLOGY AS EFFECTIVENESS MECHANISM FOR SUSTAINABLE DEVELOPMENT

OBJECTIVES IN BRAZIL

Vanessa de Castro ROSA ${ }^{2}$

Guilherme de Souza CAMPOS ${ }^{3}$

ISSUE DOI: $10.21207 / 1983.4225 . v 15.1005$

\section{RESUMO}

A Agenda 2030, construída a partir dos objetivos do milênio e das decisões tomadas na Rio+20, consiste em 17 objetivos de desenvolvimento sustentável associados a 169 metas que buscam auxiliar a comunidade internacional no processo de construção do desenvolvimento sustentável, além de se reforçar paradigma de solidariedade e sustentabilidade para o Direito e para as Relações Internacionais.

\footnotetext{
${ }^{1}$ Artigo realizado com apoio do Programa Institucional de Apoio à Pesquisa da UEMG - PAPq/UEMG (Edital no 01/2018).

${ }^{2}$ Doutora em Direito pelo Programa Doutorado em Direito Político e Econômico do Mackenzie-SP. Mestra em Direitos Humanos Fundamentais com dissertação na área de Direito Internacional Ambiental (2013). Especialização em Direito Ambiental pela UGF/CAD (2005), Especialização em Direito Processual Civil pela UNISUL/LFG (2007), Especialização em Direito Processual Penal pela UCDB/CPC (2008). Especialista em Agroecologia no Cerrado pela UEMG-Frutal (2020). Bacharela em Filosofia (Unisul). Bacharela em Direito pela UNESP (2004). Professora efetiva de Direito Agrário e Direito Ambiental na Universidade do Estado de Minas Gerais, Unidade Frutal/MG. Currículo Lattes: http://lattes.cnpq.br/9545269656567768. Contato: vanessa.rosa@uemg.br.

${ }_{3}^{3}$ Bacharel em Direito Universidade do Estado de Minas Gerais, Unidade Frutal/MG. Programa Institucional de Apoio à Pesquisa da UEMG - PAPq/UEMG (Edital $n^{\circ}$ 1/2018). Currículo Lattes: http://lattes.cnpq.br/2570418384078818. Contato: camposguilherme@hotmail.com.br.
} 
A Agenda está em vigor desde 2016 e estabelece metas para serem cumpridas até 2030, para observância destas metas e prazo, a Agroecologia mostra-se como um importante instrumento de efetivação dos objetivos de desenvolvimento sustentável (ODS), conforme estudo realizado, em 2013, pela Aliança para a Soberania Alimentar na África (AFSA) que analisou 50 casos de uso de agricultura agroecológica em 22 países africanos, constatou-se que a Agroecologia contribuiu para a atingir 10 dos 17 ODS. A partir deste estudo organizado por Michael Farrely e de autores como Enrique Leff e Miguel Altieri, compreende-se a agroecologia, como agricultura socialmente justa, economicamente viável e ecologicamente sustentável, além de campo de saber interdisciplinar, que se afirma na sociedade como teoria crítica, prática agrícola sustentável e movimento social, contribuindo para a implantação de um modelo agrícola e social sustentáveis nos moldes dos ODS. Este artigo estuda como a agroecologia, através das leis que versam sobre o tema, poderá efetivar os ODS no Brasil, por intermédio de pesquisa bibliográfica de cunho exploratório e qualitativo, cuja análise de leis, decretos, tratados e artigos especializados sobre o tema, buscará evidenciar a relação dos dispositivos legais com os ODS. Concluise que a agroecologia e o direito são instrumentos promotores dos ODS, porém, a legislação agroecológica brasileira atua de forma tímida, visto que disputa espaço com uma política agrícola direcionada para o agronegócio, de modo que a não implementação dos ODS está no campo da efetividade e não da normatividade.

Palavras-chave: Agroecologia. Objetivos de Desenvolvimento Sustentável. Agenda 2030.

\begin{abstract}
Agenda 2030, built on the objectives of the millennium and the decisions taken at Rio +20 , consists of 17 sustainable development objectives associated with 169 goals that seek to assist the international community in the process of building sustainable development, in addition to reinforce the paradigm of solidarity and sustainability for the Law and for International Relations. The Agenda has been in force since 2016 and establishes goals to be met by 2030, in order to comply with these goals and deadline, Agroecology is an important instrument for implementing the sustainable development objectives (SDGs), according to a study carried out in 2013, by the Alliance for Food Sovereignty in Africa (AFSA), which analyzed 50 use cases for agroecological agriculture in 22 African countries, it was found that Agroecology contributed to achieving 10 of the 17 SDGs. From this study organized by Michael Farrely and authors such as Enrique Leff and Miguel Altieri, agroecology is understood as a socially just, economically viable and ecologically sustainable agriculture, as well as an interdisciplinary field of knowledge, which asserts itself in society as a critical theory, sustainable agricultural practice and social movement, contributing to the implementation of a sustainable agricultural and social model along the lines of the SDGs. This article studies how agroecology, through the laws that deal with the topic, can effect the SDGs in Brazil, through exploratory and qualitative bibliographic research, whose analysis of laws, decrees, treaties and specialized articles on the subject, will seek evidence the relationship of legal provisions with the SDGs. It is concluded that agroecology and law are instruments that promote the SDGs, however, Brazilian agroecological legislation acts in a timid way, since it disputes space with an agricultural policy directed at agribusiness, so that the nonimplementation of the SDGs is in the field effectiveness and not normativity.
\end{abstract}

Keywords: Agroecology. Sustainable Development Goals. Agenda 2030.

\title{
1 INTRODUÇÃO
}

Contemporaneamente, entende-se, de modo geral, a agroecologia como a o conhecimento científico, em busca de práticas agrícolas sustentáveis que propiciem desenvolvimento sustentável para o agricultor e para o país. 
A agroecologia busca criar agroecossistemas "culturalmente sensíveis, socialmente justos e economicamente viáveis"4, apresenta-se como ciência, prática agrícola e movimento social, pois busca valorizar o conhecimento tradicional, estudando-o a partir da ciência em busca de práticas agrícolas sustentáveis para o meio ambiente e para o agricultor, além de conscientizá-los sobre a importância da agrobiodiversidade, de seus valores culturais e de uma relação produtiva com a terra mais harmônica, tanto do ponto de vista natural como econômico.

Deste modo, a agroecologia se mostra como instrumento de empoderamento social dos agricultores para a transição da agricultura convencional para uma agricultura agroecológica promotora do desenvolvimento sustentável, tornando-se, portanto, uma ferramenta para se concretizar os Objetivos de Desenvolvimentos Sustentável (ODS) propostos pela Organização das Nações Unidas.

O presente artigo, a partir do estudo feito por Michael Farelly, busca destacar o papel da agroecologia como mecanismo de efetivação dos ODS. Para tanto foi desenvolvida pesquisa bibliográfica, exploratória e qualitativa direcionada a compreensão da relação entre objetivos de desenvolvimento sustentável e agroecologia a partir das leis 10.831/03, lei 11.326/06 e do decreto 7.794/12, referentes à agricultura orgânica e agroecologia.

Espera-se mostrar a possibilidade da agroecologia em se tornar um mecanismo de efetivação dos ODS no Brasil, a partir das leis seja como normas impositivas de regramento de condutas ou como normas de fomento a adoção de práticas sustentáveis.

\section{A RELAÇÃO ENTRE AGROECOLOGIA E OBJETIVOS DE DESENVOLVIMENTO SUSTENTÁVEL}

A agroecologia busca a criação de um novo paradigma produtivo, que harmonize a produção agrícola, biodiversidade (animal e vegetal) e justiça social, para obtenção de uma produção ecologicamente sustentável ${ }^{5}$.

\footnotetext{
${ }^{4}$ ALTIERI, Miguel. Agroecologia: a dinâmica produtiva da agricultura sustentável. 5. ed. Porto Alegre: UFRGS, 2008, p. 21.

${ }^{5}$ LEFF, Enrique. Agroecologia e saber ambiental. Revista Agroecologia e Desenvolvimento Rural Sustentável, Porto Alegre, v. 3, n. 1, jan./mar. 2002, p. 36.
} 


\title{
A Associação Brasileira de Agroecologia trabalha com o seguinte conceito
}

\begin{abstract}
Agroecologia é entendida como enfoque científico, teórico, prático e metodológico, com base em diversas áreas do conhecimento, que se propõe a estudar processos de desenvolvimento sob uma perspectiva ecológica e sociocultural e, a partir de um enfoque sistêmico - adotando o agroecossistema como unidade de análise apoiar a transição dos modelos convencionais de agricultura e de desenvolvimento rural para estilos de agricultura e de desenvolvimento rural sustentável ${ }^{6}$.
\end{abstract}

E não há como se falar em desenvolvimento sustentável sem considerar a variável ambiental, que afeta a relação de diferentes sujeitos com o ambiente, tanto na construção de seu lugar, como na de sua cultura ${ }^{7}$, pois o ser humano está inserido no ambiente e o impacta e é impactado, fortemente, por ele.

Por esta razão, a Organização das Nações Unidas para a Alimentação e a Agricultura (FAO) está desenvolvendo ferramentas mais elaboradas para comparar diretamente o impacto de métodos de agricultura convencionais e agroecológicos em busca de sistemas alimentares e agrícolas sustentáveis ${ }^{8}$.

Assim, em 2015, na sede da Organização das Nações Unidas (ONU) 193 países, inclusive o Brasil, reuniram-se e aprovaram o documento "Transformando nosso futuro: a Agenda 2030 para o Desenvolvimento Sustentável", o qual entrou em vigor em 01 de janeiro de 2016, com o compromisso de ser cumprido até 2030, razão pela qual também é chamado de Agenda 2030.

Este documento foi produzido a partir dos objetivos do milênio e das decisões tomadas na Rio+20, consiste em 17 objetivos de desenvolvimento sustentável associados a 169 metas $^{9}$ que buscam auxiliar na concretização dos objetivos, como forma de auxiliar a comunidade

\footnotetext{
${ }^{6}$ ABA. Associação Brasileira de Agroecologia. Quem somos. Rio de Janeiro, [20-?]. Disponível em: http://aba-agroecologia.org.br/sobre-a-aba-agroecologia/sobre-a-aba/. Acesso em: 03 fev. 2020.

${ }^{7}$ TRUJILLO-ORTEGA, Laura Elena. Ecologia política del desarrollo sostenible. In: SAUER, Sérgio; BALESTRO, Moisés (Org.). Agroecologia e os desafios da transição agroecológica. 2. ed. São Paulo: Expressão Popular, 2013, p. 96.

${ }^{8}$ FARRELLY, Michael. Contribuições da Agroecologia para os objetivos de desenvolvimento sustentável. Revista Agriculturas, Rio de Janeiro, v. 13, n. 3, p. 80-83, set. 2016, p. 83.

${ }^{9}$ ONU. Transformando nosso mundo: a Agenda 2030 para o desenvolvimento sustentável. Nova York, 2015. Disponível em: https://nacoesunidas.org/wp-content/uploads/2015/10/agenda2030-ptbr.pdf. Acesso em: 20 jan. 2020.
} 
internacional no processo de construção do desenvolvimento sustentável, além de se reforçar paradigma de solidariedade e sustentabilidade para o Direito e para as Relações Internacionais.

Em 2013, a Aliança para a Soberania Alimentar na África (AFSA) analisou 50 estudos de casos em 22 países africanos para ressaltar a contribuição da Agroecologia para a construção de um futuro mais consistente e viável para a agricultura na África, sendo que a meta-análise dos dados colhidos apontou que a agroecologia contribui de várias formas para atingir de forma direta 10 (dez) dos 17 (dezessete) objetivos de desenvolvimento sustentável ${ }^{10}$.

Este estudo demonstra que o uso da agroecologia permitiu colaborar com os seguintes objetivos de desenvolvimento sustentável: erradicação da pobreza; fome zero e agricultura sustentável; saúde e bemestar; educação de qualidade; igualdade de gênero; água potável e saneamento; emprego decente e crescimento econômico; consumo e produção responsáveis; ação contra a mudança global do clima e melhorias na vida terrestre ${ }^{11}$.

Estes objetivos de desenvolvimento sustentável foram alcançados com o uso de técnicas agroecológicas para recuperação da fertilidade do solo, adoção do controle biológico no lugar de agrotóxicos e de sementes naturais (crioulas) no lugar de sementes transgênicas; uso racional da água; diversificação e rotação de colheitas; cultivo de plantas locais; integração entre lavouras e florestas.

Este estudo, conduzido por Michael Farrelly, também evidenciou o caráter político e social da agroecologia e sua ligação direta com o desenvolvimento sustentável, demonstrando sua potencialidade para concretizar os objetivos do desenvolvimento sustentável.

Neste sentido,

Ao destacar a contribuição da Agroecologia para um marco político tão importante como os ODS, enfatizamos a pertinência do desenvolvimento de uma política transversal de apoio a esse modelo de agricultura. Cabe agora aos decisores políticos e à

${ }^{10}$ FARRELLY, Michael. Contribuições da Agroecologia para os objetivos de desenvolvimento sustentável. Revista Agriculturas, Rio de Janeiro, v. 13, n. 3, p. 80-83, set. 2016, p. 80.

${ }^{11}$ FARRELLY, Michael. Contribuições da Agroecologia para os objetivos de desenvolvimento sustentável. Revista Agriculturas, Rio de Janeiro, v. 13, n. 3, p. 80-83, set. 2016, p. 83. 
comunidade de pesquisa agrícola reconhecer esse potencial da Agroecologia para atender às necessidades e desafios do mundo ${ }^{12}$.

A ideia de desenvolvimento sustentável trazida pelo Relatório Brundtland parte do reconhecimento da finitude dos recursos naturais e da responsabilidade perante as futuras gerações, buscando a conciliação entre desenvolvimento econômico com conservação ambiental. Nesta linha, no campo da agricultura, o desenvolvimento sustentável busca integrar a produtividade dos sistemas agrícolas com os aspectos econômicos, sociais e ambientais.

Desta forma, a agroecologia, como modelo de sustentabilidade, compartilha a base axiológica e prática dos ODS, assim, se mostra como uma ferramenta para a efetivação destes objetivos definidos pela Agenda 2030 da ONU.

\section{AGROECOLOGIA E EFETIVAÇÃO DOS ODS}

No primeiro ODS da Agenda 2030, foi fixado uma pauta de cunho socioeconômico, a erradicação da pobreza em todas as suas formas. Desta feita, foram estabelecidas metas a serem praticadas pelos Estados para o alcance deste intento, com destaque para as metas relacionadas à erradicação da pobreza extrema com redução pela metade da proporção de pessoas que vivem na pobreza e garantia de direitos iguais em relação ao acesso à terra, tecnologias e recursos financeiros necessários para a atividade agrícola ${ }^{13}$.

A doutrina agroecológica evidencia a insustentabilidade do modelo atual de agricultura praticado no Brasil, incentivando a aplicação de novas noções para uma produção agrícola mais sustentável, possibilitando o fortalecimento:

A degradação socioambiental está exigindo a impostergável necessidade de transformar os princípios da racionalidade econômica, de seu caráter desigual e depredador, para construir

\footnotetext{
${ }^{12}$ FARRELLY, Michael. Contribuições da Agroecologia para os objetivos de desenvolvimento sustentável. Revista Agriculturas, Rio de Janeiro, v. 13, n. 3, p. 80-83, set. 2016, p. 83.

${ }^{13}$ ONU. Transformando nosso mundo: a Agenda 2030 para o desenvolvimento sustentável. Nova York, 2015. Disponível em: https://nacoesunidas.org/wp-content/uploads/2015/10/agenda2030-ptbr.pdf. Acesso em: 20 jan. 2020.
} 
uma racionalidade produtiva capaz de gerar um desenvolvimento equitativo, sustentável e duradouro ${ }^{14}$.

É perceptível também, na legislação agroecológica brasileira, quais sejam, a lei 10.831/03, lei $11.326 / 06$ e decreto $7.794 / 12$, a presença de dispositivos que promovem este primeiro ODS, podendo destacar dentre eles, respectivamente: 1) a maximização dos benefícios sociais por meio da otimização do uso dos recursos naturais e socioeconômicos disponíveis; 2) o destaque dado aos beneficiários da agricultura familiar como foco de proteção e garantia do exercício de suas atividades e 3) a promoção da justiça social pela produção de base agroecológica.

O segundo ODS, que versa sobre a fome zero e agricultura sustentável, tem dentre suas metas acabar com a fome, garantindo o acesso de todos a alimentos seguros e nutritivos, por meio de uma produção agrícola sustentável que promova a resiliência do ecossistema e permita dobrar a renda dos pequenos agricultores, principalmente os beneficiários da agricultura familiar ${ }^{15}$.

$\mathrm{Na}$ legislação brasileira, buscam promovem este segundo ODS através do incentivo a oferta de produtos saudáveis isentos de contaminantes intencionais e com uso sustentável dos recursos naturais, a Lei 11.346/06, que criou o Sistema Nacional de Segurança Alimentar e Nutricional (SISAN), para assegurar o direito humano à alimentação adequada e à soberania alimentar e a lei 10.836/04, que criou o Programa Bolsa Família.

Também as leis que reconhecem e protegem as comunidades tradicionais (decreto 6.040/07), quilombolas (decreto 4.887/03) e povos originários (lei 6.001/73), possibilitando que elas continuem existindo e reproduzindo seu modo de vida tradicional, muitas vezes de base agroecológica, de modo que estas comunidades sejam autossuficientes e sustentáveis.

O terceiro ODS trata sobre a promoção da saúde e do bem-estar, definindo metas para este fim como redução da taxa de mortalidade infantil

\footnotetext{
${ }^{14}$ LEFF, Enrique. Agroecologia e saber ambiental. Revista Agroecologia e Desenvolvimento Rural Sustentável, Porto Alegre, v. 3, n. 1, jan./mar. 2002, p. 46.

${ }^{15}$ ONU. Transformando nosso mundo: a Agenda 2030 para o desenvolvimento sustentável. Nova York, 2015. Disponível em: https://nacoesunidas.org/wp-content/uploads/2015/10/agenda2030-ptbr.pdf. Acesso em: 20 jan. 2020.
} 
e materna e das doenças provenientes de produtos químicos perigosos, além da redução da contaminação e poluição dos recursos naturais ${ }^{16}$.

Assim, a agroecologia trabalha com o máximo fortalecimento do agroecossistema, evitando que este dependa de insumos externos, ainda mais os provenientes de energia não-renovável: "Uma abordagem agroecológica incentiva os pesquisadores a penetrar no conhecimento e nas técnicas dos agricultores e a desenvolver agroecossistemas com uma dependência mínima de insumos agroquímicos e energéticos externos" $"$.

Além disso, segundo o relatório de Olivier de Schutter, as organizações de agricultores preferem a agroecologia por proporcionar um ambiente agradável para quem trabalha na terra por um longo tempo, por exemplo a sombra das árvores ou a ausência de cheiro e toxicidade dos produtos químicos ${ }^{18}$.

Em relação a este ODS, as normas brasileiras sobre o tema também detêm dispositivos que o promovem, tais como, a minimização da dependência de energia não-renovável e matérias sintéticos, além da eliminação de agrotóxicos (lei 7802/89) e da redução do uso de organismos geneticamente modificados (decreto 7794/12); além de sustentabilidade ambiental, social e econômica na aplicação das políticas da agricultura familiar, bem como instrumentos que possibilitem infraestrutura e educação, possibilitando aos beneficiários o aumento da qualidade de vida e bem-estar; e a promoção da soberania e segurança alimentar e do favorecimento do bem-estar dos proprietários e trabalhadores.

Orgânica (PNAPO):

Neste sentido, a Política Nacional de Agroecologia e Produção

Art. $3^{\circ}$ São diretrizes da PNAPO:

I - promoção da soberania e segurança alimentar e nutricional e do direito humano à alimentação adequada e saudável, por meio da oferta de produtos orgânicos e de base agroecológica isentos de contaminantes que ponham em risco a saúde;

\footnotetext{
${ }^{16}$ ONU. Transformando nosso mundo: a Agenda 2030 para o desenvolvimento sustentável. Nova York, 2015. Disponível em: https://nacoesunidas.org/wp-content/uploads/2015/10/agenda2030-ptbr.pdf. Acesso em: 20 jan. 2020.

17 ALTIERI, Miguel. Agroecologia: a dinâmica produtiva da agricultura sustentável. 5. ed. Porto Alegre: UFRGS, 2008, p. 23.

${ }^{18}$ SCHUTTER, Olivier de. A agroecologia e o direito humano à alimentação. Caderno SISAN 01/2012. [S. l.]: CAISAN, 2012.
} 
II - promoção do uso sustentável dos recursos naturais, observadas as disposições que regulem as relações de trabalho e favoreçam o bem-estar de proprietários e trabalhadores;

III - conservação dos ecossistemas naturais e recomposição dos ecossistemas modificados, por meio de sistemas de produção agrícola e de extrativismo florestal baseados em recursos renováveis, com a adoção de métodos e práticas culturais, biológicas e mecânicas, que reduzam resíduos poluentes e a dependência de insumos externos para a produção;

IV - promoção de sistemas justos e sustentáveis de produção, distribuição e consumo de alimentos, que aperfeiçoem as funções econômica, social e ambiental da agricultura e do extrativismo florestal, e priorizem o apoio institucional aos beneficiários da Lei $\underline{\mathrm{n}^{\circ} 11.326, \text { de 2006; }}$

V - valorização da agrobiodiversidade e dos produtos da sociobiodiversidade e estímulo às experiências locais de uso e conservação dos recursos genéticos vegetais e animais, especialmente àquelas que envolvam $\mathrm{o}$ manejo de raças $\mathrm{e}$ variedades locais, tradicionais ou crioulas;

VI - ampliação da participação da juventude rural na produção orgânica e de base agroecológica; e

VII - contribuição na redução das desigualdades de gênero, por meio de ações e programas que promovam a autonomia econômica das mulheres ${ }^{19}$.

Estas diretrizes positivam medidas agroecológicas que permitem a concretização dos Objetivos de Desenvolvimento Sustentável a partir da agroecologia. Assim, tal como o estudo realizado por Michael Farrelly, a legislação nacional aponta para a construção de um modelo de desenvolvimento sustentável a partir da agroecologia.

No quarto objetivo de desenvolvimento sustentável, a Agenda definiu o objetivo de alcançar a educação de qualidade, inclusiva e equitativa a todos, desde o primário até a técnica e profissional. Dentre suas metas, é possível destacar a garantia de igualdade de acesso, por todos e independentemente de seu gênero, deficiência, etnia ou condição social, à

\footnotetext{
${ }^{19}$ BRASIL. Decreto no 7.794, de 20 de agosto de 2012. Institui a Política Nacional de Agroecologia e Produção Orgânica. Brasília-DF: Presidência da República, 2012. Disponível em: http://www.planalto.gov.br/ccivil_03/ ato2011-2014/2012/decreto/d7794.htm. Acesso em: 27 fev. 2020.
} 
educação técnica, profissional e superior a preços acessíveis, possibilitando maiores possibilidades de conquistarem empregos e trabalhos decentes ${ }^{20}$.

A educação e formação profissional é um instrumento para a concretização da Política Nacional de Agroecologia e Produção Orgânica, prevista no art. $4^{\circ}$, IX do decreto 7.794/12 21 e também a Lei de Educação Ambiental estabelece como dever do Poder Público incentivar, entre outros objetivos, a sensibilização da sociedade, dos agricultores e das populações tradicionais sobre a temática ambiental ${ }^{22}$.

Também faz parte do quarto ODS, assegurar que todos os alunos e alunas tenham uma educação voltada ao desenvolvimento sustentável, com estilos de vida sustentáveis, igualdade de gênero e valorização da diversidade cultural ${ }^{23}$.

Neste seguimento, destaca-se o papel da agroecologia como conjunto de saberes e técnicas calcadas na sustentabilidade, pois "os saberes agroecológicos são uma constelação de conhecimentos, técnicas, saberes e práticas dispersas que respondem às condições ecológicas, econômicas, técnicas e culturais de cada geografia e de cada população"24.

Portanto, a sustentabilidade agroecológica não se dispõe a ficar somente na seara ambiental, mas alcança multidimensões que:

Na realidade concreta elas se influem uma à outra e interagem o tempo todo, de modo que estudá-las, entendê-las e propor alternativas mais sustentáveis supõe, necessariamente, uma abordagem inter, multi e transdisciplinar, razão pela qual os agroecólogos lançam mão de ensinamentos presentes no saber popular, mas também de conhecimentos gerados no âmbito da Física, da Economia Ecológica e Ecologia Política, da Agronomia

\footnotetext{
${ }^{20}$ ONU. Transformando nosso mundo: a Agenda 2030 para o desenvolvimento sustentável. Nova York, 2015. Disponível em: https://nacoesunidas.org/wp-content/uploads/2015/10/agenda2030-ptbr.pdf. Acesso em: 20 jan. 2020.

${ }^{21}$ BRASIL. Decreto $\mathbf{n}^{\mathbf{0}}$ 7.794, de 20 de agosto de 2012. Institui a Política Nacional de Agroecologia e Produção Orgânica. Brasília-DF: Presidência da República, 2012. Disponível em: http://www.planalto.gov.br/ccivil_03/_ato2011-2014/2012/decreto/d7794.htm. Acesso em: 27 fev. 2020.

${ }^{22}$ BRASIL. Lei no 9.795, de 27 de abril de 1999. Dispõe sobre a educação ambiental, institui a Política Nacional de Educação Ambiental e dá outras providências. Brasília-DF: Presidência da República, 1999. Disponível em: http://www.planalto.gov.br/ccivil 03/LEIS/L9795.htm. Acesso em: 27 fev. 2020.

${ }^{23}$ ONU. Transformando nosso mundo: a Agenda 2030 para o desenvolvimento sustentável. Nova York, 2015. Disponível em: https://nacoesunidas.org/wp-content/uploads/2015/10/agenda2030-ptbr.pdf. Acesso em: 20 jan. 2020.

${ }^{24}$ LEFF, Enrique. Agroecologia e saber ambiental. Revista Agroecologia e Desenvolvimento Rural Sustentável, Porto Alegre, v. 3, n. 1, jan./mar. 2002, p. 37.
} 
[...], da História, da Antropologia e da Sociologia, para ficarmos apenas em alguns exemplos que orientam esta reflexão ${ }^{25}$.

O quinto ODS trata do tema da igualdade de gênero, visando metas para o empoderamento feminino. No interior destas metas, destacase $\mathrm{o}$ fim de todas as formas de discriminação contra mulheres, reconhecendo seu trabalho de assistência doméstico e inclusive garantindo a participação plena, efetiva e de igual oportunidades em todos os níveis da vida política, econômica e pública, além de promover direitos iguais às mulheres para o acesso aos recursos econômicos e naturais, bem como o acesso a propriedade e controle sobre a terra ${ }^{26}$.

Nesta linha, a Política Nacional da Agricultura Familiar e Empreendimentos Familiares Rurais estabelece, em seu art. $4^{\circ}$, como princípio norteador a equidade na aplicação das políticas, respeitando os aspectos de gênero, geração e etnia ${ }^{27}$ e a Política Nacional de Agroecologia e Produção Orgânica estabelece como diretriz a contribuição na redução das desigualdades de gênero, por meio de ações e programas que promovam a autonomia econômica das mulheres ${ }^{28}$.

$\mathrm{Na}$ agroecologia se constrói sobre "metodologias participativas, garantias de acesso aos direitos básicos de cidadania, respeitos às diferenças culturais, de gênero, de raça, de etnia" 29 .

Em complemento a esta ideia, Olivier de Schutter elenca que:

Devem ser formulados planos específicos com objetivos concretos para empoderar e estimular a participação das mulheres nesta construção de conhecimento. [...] Em princípio, a agroecologia pode beneficiar mais as mulheres, porque são elas que encontram mais dificuldades no acesso aos insumos ou subsídios externos. Mas não se deve supor que a possibilidade das mulheres acessarem

\footnotetext{
${ }^{25}$ CAPORAL, Francisco Roberto; AZEVEDO, Edisio Oliveira de (Org.). Princípios e perspectivas da agroecologia. [S. l.]: IFPRM 2011, p. 52.

${ }^{26}$ ONU. Transformando nosso mundo: a Agenda 2030 para o desenvolvimento sustentável. Nova York, 2015. Disponível em: https://nacoesunidas.org/wp-content/uploads/2015/10/agenda2030-ptbr.pdf. Acesso em: 20 jan. 2020.

${ }^{27}$ Brasil. Lei $\mathbf{~ n}^{\mathbf{0}}$ 11.326, de 24 de julho de 2006. Estabelece as diretrizes para a formulação da Política Nacional da Agricultura Familiar e Empreendimentos Familiares Rurais. Brasília-DF: Presidência da República, 2006. Disponível em: http://www.planalto.gov.br/ccivil 03/ Ato20042006/2006/Lei/L11326.htm. Acesso em: 27 fev. 2020.

${ }^{28}$ BRASIL. Decreto n $\mathbf{~}^{\mathbf{7} .794}$, de 20 de agosto de 2012. Institui a Política Nacional de Agroecologia e Produção Orgânica. Brasília-DF: Presidência da República, 2012. Disponível em: http://www.planalto.gov.br/ccivil 03/ ato2011-2014/2012/decreto/d7794.htm. Acesso em: 27 fev. 2020.

${ }^{29}$ CAPORAL, Francisco Roberto; AZEVEDO, Edisio Oliveira de (Org.). Princípios e perspectivas da agroecologia. [S. l.]: IFPRM 2011, p. 100.
} 
a agroecologia gerará resultados automáticos, é fundamental que sejam realizadas ações afirmativas dirigidas especialmente às mulheres ${ }^{30}$.

Destarte, na legislação brasileira, o empoderamento das mulheres verifica-se em duas das três normas analisadas, a lei 11.326/06 e o decreto 7.794/12, como forma de promover a equidade na aplicação das políticas da agricultura familiar, respeitando os aspectos de gênero, geração e etnia e a contribuição na redução das desigualdades de gênero, por meio de ações e programas que promovam a autonomia econômica das mulheres, na política agroecológica.

O sexto ODS sustenta-se na garantia de disponibilidade e gestão sustentável da água e saneamento para todos, definindo como metas a melhoria da qualidade da água, reduzindo a poluição e eliminando o despejo de produtos químicos e materiais perigosos, bem como o aumento da eficiência do uso da água, para o fim da escassez garantindo-se o abastecimento de água doce para todas as pessoas ${ }^{31}$.

Também foram definidas metas para proteger e restaurar os ecossistemas relacionados com a água, além do apoio e fortalecimento da participação das comunidades locais na gestão dos recursos hídricos ${ }^{32}$.

Contrariamente a este ODS, "a contaminação das águas por pesticidas e fertilizantes químicos usados de forma abusiva e intensiva [...] tem crescido a cada dia. Há inclusive, estudos mostrando a presença de agroquímicos nas águas do Aquífero Guarani [...]"33.

Neste sentido, a agroecologia propõe a eliminação de agrotóxicos e o manejo consciente e sustentável dos recursos naturais produz técnicas que tornam eficientes o uso dos recursos hídricos na produção agrícola:

Os princípios do manejo incluem a captação de água e de nutrientes das bacias hidrográficas, reciclagem dos nutrientes na propriedade, manejo do fluxo de nutrientes da propriedade para os consumidores

\footnotetext{
${ }^{30}$ SCHUTTER, Olivier de. A agroecologia e o direito humano à alimentação. Caderno SISAN 01/2012. [S. l.]: CAISAN, 2012, p. 29-30.

${ }^{31}$ ONU. Transformando nosso mundo: a Agenda 2030 para o desenvolvimento sustentável. Nova York, 2015. Disponível em: https://nacoesunidas.org/wp-content/uploads/2015/10/agenda2030-ptbr.pdf. Acesso em: 20 jan. 2020.

32 ONU. Transformando nosso mundo: a Agenda 2030 para o desenvolvimento sustentável. Nova York, 2015. Disponível em: https://nacoesunidas.org/wp-content/uploads/2015/10/agenda2030-ptbr.pdf. Acesso em: 20 jan. 2020.

${ }^{33}$ CAPORAL, Francisco Roberto; AZEVEDO, Edisio Oliveira de (Org.). Princípios e perspectivas da agroecologia. [S. l.]: IFPRM 2011, p. 139.
} 
e de volta à propriedade, uso ponderado dos recursos hídricos, aumento da biodiversidade e uso de fontes renováveis de energia ${ }^{34}$.

Neste cenário, a lei 10.831/03 incentiva o sistema orgânico de produção organizado localmente, com a promoção do uso saudável da água, reduzindo ao mínimo todas as formas de contaminação desse elemento; a sustentabilidade ambiental como princípio da política da agricultura familiar, vinculando a produção agrícola familiar ao manejo sustentável dos recursos naturais da propriedade e a produção orgânica e de base agroecológica que promove o uso sustentável dos recursos naturais, com conservação e recomposição dos ecossistemas modificais, além da redução de resíduos poluentes.

Ao lado das leis agroecológicas, a água é tratada de forma específica na Política Nacional de Recursos Hídricos (Lei 9433/97) e o saneamento básico, na lei 11.445/07.

O oitavo ODS fixou o propósito de promover o crescimento econômico de forma sustentável e associado à oferta de emprego pleno, produtivo e decente a todos. Entre as metas deste objetivo, estão a melhoria da eficiência dos recursos globais no consumo e na produção, dissociando o crescimento econômico da degradação ambiental, a proteção de direitos trabalhistas e promoção de ambientes de trabalho seguros e a promoção do turismo sustentável, da cultura e dos produtos locais.

A agroecologia valoriza não só os conhecimentos e técnicas do agricultor, mas também reconhece e valoriza a força do trabalho empregada por este no processo de produção agrícola:

[...] a Agroecologia se encrava no contexto de uma economia política do ambiente. Desta maneira, devolve o sentido à força de trabalho como labor produtivo que trabalha com forças da natureza, onde o trabalho, dentro de conjunto de práticas, não só é conduzido por saberes e conhecimentos práticos, mas por uma teoria que os envolve em uma estratégia política que os conduz e os faz valer ${ }^{35}$.

A agricultura camponesa e a agroecologia promovem geração de renda e trabalho, através do planejamento de tecnologias apropriadas que

\footnotetext{
${ }^{34}$ ALTIERI, Miguel. Agroecologia: a dinâmica produtiva da agricultura sustentável. 5. ed. Porto Alegre: UFRGS, 2008, p. 110.

35 LEFF, Enrique. Agroecologia e saber ambiental. Agroecologia e Desenvolvimento Rural Sustentável, Porto Alegre, ano 3, n. 1, p. 36-51, jan./mar. 2002, p. 40. Disponível em: http://www.emater.tche.br/site/multimidia/leitor/10.php. Acesso em: 18 fev. 2020.
} 
aumentam o valor agregado dos produtos agrícolas das pequenas propriedades $^{36}$.

As leis 10.831/03, a lei de agricultura familiar (lei 11.326/06) o decreto 7.794/12 sobre produção agroecológica e orgânica buscam promover este oitavo ODS, a exemplo: 1) do sistema orgânico de produção que preserva a diversidade biológica dos ecossistemas naturais e promove o uso saudável dos recursos naturais, além da regionalização da produção e comércio desses produtos; 2) de princípios como a descentralização e sustentabilidade ambiental, social e econômica, bem como equidade na aplicação das políticas, como acesso aos instrumentos para a atividade agrícola, da agricultura familiar; e 3) da produção orgânica e de base agroecológica que promove o uso sustentável dos recursos naturais e observa os direitos trabalhistas, favorecendo o bem-estar de proprietários e trabalhadores.

A redução da desigualdade dentro dos países e entre eles é o décimo objetivo da Agenda 2030, que traz como metas: a promoção da inclusão social, econômica e política de todos, independente do gênero, deficiência, etnia, condição econômica e a garantia de igualdade de oportunidades e redução das desigualdades de resultados ${ }^{37}$.

Nas leis que tratam sobre agroecologia, o Brasil adota medidas para implementação deste objetivo, como sistemas agrícolas organizados localmente, com regionalização da produção e comércio de produtos orgânicos; princípios de descentralização, sustentabilidade socioeconômica e equidade na aplicação das políticas da agricultura familiar aos beneficiários desta e valorização dos produtos da sociobiodiversidade e promoção de sistemas justos e sustentáveis de produção, distribuição e consumo de alimentos, priorizando a agricultura familiar.

No décimo primeiro ODS, as metas colocadas têm como finalidade garantir o acesso a serviços básicos e à habitação segura, adequada com preços acessíveis, promoção de urbanização inclusiva e sustentável, além de planejamento e gestão para assentamentos humanos participativos integrados e sustentáveis, inclusive com garantia de

\footnotetext{
${ }^{36}$ ALTIERI, Miguel. Agroecologia: a dinâmica produtiva da agricultura sustentável. 5. ed. Porto Alegre: UFRGS, 2008, p. 109.

${ }^{37}$ ONU. Transformando nosso mundo: a Agenda 2030 para o desenvolvimento sustentável. Nova York, 2015. Disponível em: https://nacoesunidas.org/wp-content/uploads/2015/10/agenda2030-ptbr.pdf. Acesso em: 20 jan. 2020.
} 
eficiência dos recursos e aumento da capacidade de resiliência a desastres e mudanças climáticas ${ }^{38}$.

Seguindo esta linha de pensamento, na agroecologia, para que ocorra a eficiência dos seus manejos sustentáveis, é necessário que haja: "uma organização social que proteja a integridade dos recursos naturais e estimule a interação harmônica entre os seres humanos, o agroecossistema e o ambiente" 39 , a fim de que os resultados obtidos beneficiem não somente a produção em si, mas alcancem uma dimensão também comunitária.

Neste sentido, as leis 10.831/03, 11.326/06 e o decreto 7.794/12 apresentaram pontos promotores deste ODS, quais sejam: o uso sustentável dos recursos naturais com sistemas agrícolas organizados localmente, com a regionalização da produção e comércio dos produtos orgânicos; adoção de instrumentos que buscam dar infraestrutura, habitação, educação e promover o cooperativismo e associativismo para os beneficiários dos programas de produção orgânica e de base agroecológica, com a promoção de sistemas justos e sustentáveis desde a produção até o consumo dos alimentos.

O décimo segundo ODS busca assegurar uma produção e consumo sustentáveis para todos. As metas definidas são no sentido de promover programas de produção e consumo sustentáveis, com gestão sustentável e uso eficiente dos recursos naturais, bem como a redução do uso de produtos químicos e poluentes no ambiente, redução do desperdício de alimentos e promoção da prevenção, redução reciclagem e uso de resíduos ${ }^{40}$.

Também prevê a finalidade de monitorar os impactos do desenvolvimento sustentável para o turismo sustentável, promovendo a cultura e os produtos locais ${ }^{41}$.

A agroecologia propõe a adoção de agroecossistemas a fim de garantir produtividade, sem depleção dos recursos naturais, ou seja, adere-

\footnotetext{
${ }^{38}$ ONU. Transformando nosso mundo: a Agenda 2030 para o desenvolvimento sustentável. Nova York, 2015. Disponível em: https://nacoesunidas.org/wp-content/uploads/2015/10/agenda2030-ptbr.pdf. Acesso em: 20 jan. 2020.

39 ALTIERI, Miguel. Agroecologia: a dinâmica produtiva da agricultura sustentável. 5. ed. Porto Alegre: UFRGS, 2008, p. 27.

${ }^{40}$ ONU. Transformando nosso mundo: a Agenda 2030 para o desenvolvimento sustentável. Nova York, 2015. Disponível em: https://nacoesunidas.org/wp-content/uploads/2015/10/agenda2030-ptbr.pdf. Acesso em: 20 jan. 2020.

${ }^{41}$ ONU. Transformando nosso mundo: a Agenda 2030 para o desenvolvimento sustentável. Nova York, 2015. Disponível em: https://nacoesunidas.org/wp-content/uploads/2015/10/agenda2030-ptbr.pdf. Acesso em: 20 jan. 2020.
} 
se ao princípio da produtividade ecotecnológica ${ }^{42}$, reduzindo o uso de componentes externos, gerando menos resíduos e facilitando a promoção da reciclagem e do reuso de recursos próprios do ecossistema.

As três leis analisadas promovem de forma plausível este ODS, com destaque para alguns pontos como a produção e oferta de produtos saudáveis, a preservação e recomposição dos ecossistemas, o uso sustentável dos ecossistemas, a reciclagem de resíduos orgânicos, com redução de recursos não-renováveis, valorização dos produtos da sociobiodiversidade, segundo as práticas e saberes do agricultor local, além da promoção da soberania e segurança alimentares, associado a sistemas justos e sustentáveis de produção distribuição e consumo de alimentos.

Em relação ao décimo terceiro ODS, o fim a ser alcançado é o combate a mudança climática e seus impactos. Para tanto, as metas que compõem este ODS são postas para reforçar a resiliência e capacidade de adaptação às mudanças climáticas e catástrofes naturais em todos os países, integrar medidas da mudança climática nas políticas nacionais e promover o planejamento e gestão eficaz relacionado à mudança do clima, com foco nas mulheres, jovens e comunidades locais e marginalizadas ${ }^{43}$.

Nos sistemas agrícolas de produção convencionais, o modelo de monocultura tem sido responsável pelo crescente desequilíbrio ecológico resultante da simplificação do agroecossistema.

Ademais, "[...] um modelo simplificado [...] tende a ser mais susceptível às mudanças climáticas, porque os sistemas agropecuários dominantes apresentam baixa capacidade de resiliência e alto grau de instabilidade ante a eventuais distúrbios climáticos"44.

A agroecologia, por sua vez, melhora a resiliência à mudança climática, seja pelos seus métodos de diversidade de espécies e de atividade agrícolas, como também pela desvinculação da dependência de energia fóssil que elimina gases do efeito estufa ${ }^{45}$.

\footnotetext{
${ }^{42}$ LEFF, Enrique. Agroecologia e saber ambiental. Agroecologia e Desenvolvimento Rural Sustentável, Porto Alegre, ano 3, n. 1, p. 36-51, jan./mar. 2002, p. 38. Disponível em: http://www.emater.tche.br/site/multimidia/leitor/10.php. Acesso em: 18 fev. 2020.

${ }^{43}$ ONU. Transformando nosso mundo: a Agenda 2030 para o desenvolvimento sustentável. Nova York, 2015. Disponível em: https://nacoesunidas.org/wp-content/uploads/2015/10/agenda2030-ptbr.pdf. Acesso em: 20 jan. 2020.

${ }^{44}$ CAPORAL, Francisco Roberto; AZEVEDO, Edisio Oliveira de (Org.). Princípios e perspectivas da agroecologia. [S. l.]: IFPRM 2011, p. 136.

${ }^{45}$ SCHUTTER, Olivier de. A agroecologia e o direito humano à alimentação. Caderno SISAN 01/2012. [S. l.]: CAISAN, 2012.
} 
No tocante ao décimo quinto ODS, o foco central é a gestão, proteção, recuperação e promoção do uso sustentável dos ecossistemas terrestres, combatendo a desertificação e assegurando a biodiversidade. Dentre as metas fixadas pela Agenda 2030, destacam-se a conservação, recuperação e uso sustentável de ecossistemas terrestres e de água doce, com especial atenção às florestas e sua gestão sustentável ${ }^{46}$.

Neste item, a compatibilidade é completa, pois na "agroecologia, a preservação e ampliação da biodiversidade dos agroecossistemas é o primeiro princípio utilizado para produzir autorregulação e sustentabilidade" ${ }^{47}$.

Deste modo, a Política Nacional de Agricultura Orgânica e a Política Nacional de Agroecologia e Produção Orgânica buscam promover este ODS, enfatizando pontos como a preservação e recomposição da biodiversidade dos ecossistemas, a incrementação da atividade biológica e da fertilidade do solo e a promoção do uso saudável dos recursos naturais, reduzindo as suas formas de contaminação e a promoção de sistemas justos e sustentáveis de produção, com valorização da agrobiodiversidade.

\section{CONSIDERAÇÕES FINAIS}

A agroecologia como ciência que valoriza o conhecimento tradicional na construção de modelo de produção agrícola sustentável tem como objeto também o empoderamento social do produtor e das comunidades agrícolas, a fim de que possam ser sujeitos ativos de suas próprias vidas e possam viver com dignidade e independência no campo, em harmonia com os recursos naturais e produzindo alimentos saudáveis.

Em 2015, a ONU lançou a Agenda 2030, veiculando os Objetivos de Desenvolvimento Sustentável, uma readequação dos objetivos do milênio, a fim de promover desenvolvimento, crescimento e sustentabilidade, combatendo a pobreza e a exploração e contaminação do meio ambiente como um todo.

\footnotetext{
${ }^{46}$ ONU. Transformando nosso mundo: a Agenda 2030 para o desenvolvimento sustentável. Nova York, 2015. Disponível em: https://nacoesunidas.org/wp-content/uploads/2015/10/agenda2030-ptbr.pdf. Acesso em: 20 jan. 2020.

47 ALTIERI, Miguel. Agroecologia: a dinâmica produtiva da agricultura sustentável. 5. ed. Porto Alegre: UFRGS, 2008, p. 24.
} 
Na África, em 2014, foi desenvolvido por Michael Farrelly, um estudo que analisou 50 casos em 22 países africanos para ressaltar a contribuição da Agroecologia para a construção de um futuro mais consistente e viável para a agricultura na África. Neste estudo, constatouse que a meta-análise dos dados colhidos apontou que a agroecologia contribui de várias formas para atingir de forma direta 10 (dez) dos 17 (dezessete) Objetivos de Desenvolvimento Sustentável.

$\mathrm{E}$, analisando as leis brasileiras que tratam da agroecologia - lei 10.831/03 (Lei de Produção Orgânica), lei 11.326/06 (Lei Política Nacional da Agricultura Familiar) e decreto 7.794/12 (Política Nacional de Agroecologia) - é possível perceber que estas leis buscam construir um modelo sustentável e agroecológico de produção agrícola.

Estas leis que versam sobre agroecologia se apresentam como instrumento apto a efetivar os Objetivos de Desenvolvimento Sustentável, tal como o preconizado no estudo de Michael Farrelly, o qual evidenciou a relação direta entre agroecologia e ODS.

Porém, no Brasil, não são implementadas em escala macro, restringindo-se aos pequenos e médios produtores rurais, o que mostra um descompasso político entre a política nacional e o compromisso internacional firmado na Agenda 2030 das Nações Unidas, mas este descompasso é político e não jurídico.

Destarte, pode-se apontar nestas leis a existência de um direito agroecológico, que institui diretrizes políticas e jurídicas, princípios, instrumentos e deveres ao Poder Público para a concretização de um modelo de desenvolvimento sustentável agroecológico, porém, se restringe aos pequenos e médios agricultores e povos tradicionais, haja vista que o foco político e econômico ainda é o agronegócio, relegando a agricultura agroecológica a um segundo plano.

Por esta razão, o Brasil, provavelmente, continuará a encontrar dificuldades para se alcançar as metas estatuídas pela Agenda 2030, enquanto não implementar de forma efetiva os mecanismos e institutos jurídicos agroecológicos, o que evidencia que o problema para se cumprir a agenda de desenvolvimento sustentável proposta pela ONU é essencialmente político e não jurídico. 


\section{REFERÊNCIAS BIBLIOGRÁFICAS}

ABA. Associação Brasileira de Agroecologia. Quem somos. Rio de Janeiro, [20-?]. Disponível em: http://aba-agroecologia.org.br/sobre-a-aba-agroecologia/sobre-a-aba/. Acesso em: 03 fev. 2020.

ALMEIDA, Jalcione. Da ideologia do progresso à ideia de desenvolvimento (rural) sustentável. In: ALMEIDA, J.; NAVARRO, Z. (Org.). Reconstruindo a agricultura: ideias e ideais na perspectiva do desenvolvimento rural sustentável. Porto Alegre: Editora da Universidade (UFRGS), 1997.

ALTIERI, Miguel. Agroecologia: bases científicas para uma agricultura sustentável. 3. ed. São Paulo: Expressão Popular; Rio de Janeiro: AS-PTA, 2012.

ALTIERI, Miguel. Agroecologia: a dinâmica produtiva da agricultura sustentável. 5. ed. Porto Alegre: UFRGS, 2008.

BRASIL. Lei no 9.795, de 27 de abril de 1999. Dispõe sobre a educação ambiental, institui a Política Nacional de Educação Ambiental e dá outras providências. Brasília-DF: Presidência da República, 1999. Disponível em: http://www.planalto.gov.br/ccivil 03/LEIS/L9795.htm. Acesso em: 27 fev. 2020.

Brasil. Lei n 11.326, de 24 de julho de 2006. Estabelece as diretrizes para a formulação da Política Nacional da Agricultura Familiar e Empreendimentos Familiares Rurais. Brasília-DF: Presidência da República, 2006. Disponível em: http://www.planalto.gov.br/ccivil 03/Ato20042006/2006/Lei/L11326.htm. Acesso em: 27 fev. 2020.

BRASIL. Decreto no 7.794, de 20 de agosto de 2012. Institui a Política Nacional de Agroecologia e Produção Orgânica. Brasília-DF: Presidência da República, 2012. Disponível em: http://www.planalto.gov.br/ccivil_03/_ato2011-2014/2012/decreto/d7794.htm. Acesso em: 27 fev. 2020.

CAPORAL, Francisco Roberto; AZEVEDO, Edisio Oliveira de (Org.). Princípios e perspectivas da agroecologia. [S. l.]: IFPRM 2011.

CAPORAL, Francisco Roberto. Poderá a Agroecologia responder aos cinco axiomas da sustentabilidade? Revista Brasileira de Agroecologia, [s. l.], v. 11, n. 4, dez. 2016. Disponível em: http://revistas.aba-agroecologia.org.br/index.php/rbagroecologia/article/view/20668. Acesso em: 19 dez. 2018.

FARRELLY, Michael. Contribuições da Agroecologia para os objetivos de desenvolvimento sustentável. Revista Agriculturas, Rio de Janeiro, v. 13, n. 3, p. 80-83, set. 2016.

LEFF, Enrique. Agroecologia e saber ambiental. Agroecologia e Desenvolvimento Rural Sustentável, Porto Alegre, ano 3, n. 1, p. 36-51, jan./mar. 2002. Disponível em: http://www.emater.tche.br/site/multimidia/leitor/10.php. Acesso em: 18 fev. 2020.

LEFF, Enrique. Ecologia Política: uma perspectiva latino-americana. Revista Desenvolvimento e Meio Ambiente, Curitiba, v. 35, p. 29-64, dez. 2015. Disponível em: https://revistas.ufpr.br/made/article/view/44381. Acesso em: 19 dez. 2019.

ONU. Transformando nosso mundo: a Agenda 2030 para o desenvolvimento sustentável. Nova York, 2015. Disponível em: https://nacoesunidas.org/wp-content/uploads/2015/10/agenda2030-ptbr.pdf. Acesso em: 20 jan. 2020. 
SCHUTTER, Olivier de. A agroecologia e o direito humano à alimentação. Caderno SISAN 01/2012. [S. l.]: CAISAN, 2012.

TRUJILLO-ORTEGA, Laura Elena. Ecologia política del desarrollo sostenible. In: SAUER, Sérgio; BALESTRO, Moisés (Org.). Agroecologia e os desafios da transição agroecológica. 2. ed. São Paulo: Expressão Popular, 2013. 